\title{
Factors Influencing Prescribing Decisions Among Primary Health Care Physicians in Al-Buraimi Governorate, Oman
}

\author{
Hilal Salim Al Shamsi ${ }^{1}$, Talib Salim Al Kalbani ${ }^{2}$, Abdullah Ghthaith Almutairi ${ }^{3}$ \& Sulaiman Salim Al Mashrafi ${ }^{4}$ \\ ${ }^{1}$ Directorate of Planning and Studies, Directorate General of Health Services, Al-Buraimi Governorate, Ministry \\ of Health, Oman \\ ${ }^{2}$ Directorate of Pharmacy and Medical Stores, Directorate General of Health Services, Al-Buraimi Governorate, \\ Ministry of Health, Oman \\ ${ }^{3}$ Quality and Patients Safety Department, Prince Nasser bin Saad Hospital, Al-Ghat Province, Ministry of Health, \\ Saudi Arabia \\ ${ }^{4}$ Directorate General of Planning and Studies, Department of Health Information and Statistics, Muscat, Ministry \\ of Health, Oman
}

Correspondence: Hilal Salim Al Shamsi, Directorate of Planning and Studies, Directorate General of Health Services, Al-Buraimi Governorate, Ministry of Health, Oman

Received: October 24, 2018 Accepted: December 18, 2018 Online Published: March 7, 2019

doi:10.5539/gjhs.v11n4p12 URL: https://doi.org/10.5539/gjhs.v11n4p12

\begin{abstract}
Prescribing plays a major role in the activities practiced by physicians. The vast majority of health care consultations occur in the primary health care (PHC) system, where medication errors are more likely and can even be potentially life threatening. The goal of this study is to explore the factors affecting prescribing decisions among physicians working in PHC institutions in Al-Buraimi Governorate, Oman using a cross-sectional survey. Of the 53 physicians who received the questionnaire, 41 (77.4\%) completed it. The Cronbach's alpha of the instrument was 0.913 . The main patient factors that influenced prescribing decisions were age group (78\%), gender (75.6\%), and medication preference or untruthful patients $(70.7 \%)$. The main physician factors were the lack of treatment alternatives $(70.7 \%)$, doctor-patient relationship $(68.3 \%)$, strict policies and guidelines $(65.9 \%)$ and avoiding problems of drug unavailability (65.9\%). The pharmacist influenced prescribing decisions for $36.6 \%$ of physicians. The methods used for keeping physician s' medical knowledge up to date were private reading and the Internet ( $87.8 \%$ and $80.5 \%$, respectively). Sources of prescribing guidance were colleagues and evidenced-based medicine websites (78.0\% and $70.7 \%$, respectively). The current study sheds some light on the factors and behaviours that influence physician prescribing decisions in PHCs in Al-Buraimi Governorate, Oman. Additionally, this study could be used for developing policies to improve drug selections and to increase clinical and economic effectiveness and efficiency.
\end{abstract}

Keywords: factors, prescribing decision, primary health care (PHC), Oman

\section{Introduction}

The complexity of prescribing decisions might lead to irrational prescribing, which is a public health problem with the potential to harm both the individual and society (Mossialos, Walley, \& Mrazek, 2004). It is possibly a contributory factor to increased pharmaceutical expenditure worldwide (Organisation for Economic Co-operation and Development, 2007). Incorrectly prescribing drugs is a serious problem, particularly among vulnerable groups such as the elderly, who receive nearly half of all prescription items (Royal College of Physicians, 2000). Furthermore, this can lead to higher hospital admissions and avoidable costs (Beijer \& De Blaey, 2002; Tamblyn et al., 1994).

Medication errors are another concern at the primary health care (PHC) level, where they are more likely to be clinically significant (Neyaz et al., 2011). The extent of this hidden health problem is greater in rapidly developing countries than in developed countries (Neyaz et al., 2011). A study undertaken in Saudi Arabia revealed that about $12 \%$ of prescriptions in PHC settings had one or more prescribing errors, which ranged from trivial to potentially life threatening (Khoja, Al-Shammari, Farag, \& Al-Mazrou, 1996). In addition, the consequences of the above can include a loss of health, quality of life and benefits for patients and society as well as increased health care 
expenditure (O'Mahony \& Gallagher, 2008). The goal of this study is to explore the factors influencing prescribing behaviour among PHC physicians in Oman and to assess the quality of current prescribing habits.

\section{Materials and Methods}

A descriptive cross-sectional design was chosen for this study, and it was carried out at Al-Buraimi Governorate in Oman during the period of October 2013 to May 2014. All physicians working in governmental PHC institutions, including both health centres and extended health centres, in Al-Buraimi Governorate were included. There were a total of 41 out of 53 physicians included in this study: 6 physicians from health centres and 35 physicians from extended health centres.

A self-reported questionnaire was developed by the researcher specifically for this study to determine the factors influencing prescribing decisions. The questionnaire was divided into six sections (sociodemographics, patient factors, physician factors, pharmacist factors, methods of keeping medical knowledge up to date and sources of prescribing guidance). Closed-ended questions were used in the questionnaire. Responses were scored on a Likert scale, and responses for each item were arranged into groups of three: Group 1 was the summation of disagree/strongly disagree responses, Group 2 was the summation of neutral responses and Group 3 was the summation of agree/strongly agree responses.

The inclusion criteria was any physician working in the Ministry of Health at a PHC institutions. Physicians working in regional hospital facilities were excluded from this study. This is because of the complexity of the cases presented at clinics and because most hospital cases are referred from PHC institutions. Additionally, any physicians who were on annual leave were excluded from this study.

All responses in the questionnaire were coded and then imported into SPSS software for proper analysis. Descriptive statistics were used to analyze the sociodemographic data obtained from the research (i.e., frequency distribution, percentile). After grouping the responses and excluding Group 2 (neutral responses), chi-squared tests were used to examine the effects of patients, physicians, pharmacists, methods of keeping medical knowledge up to date and sources of prescribing guidance on prescribing decisions. The level of significance was set at $\mathrm{p} \leq 0.05$.

\section{Results}

A total of 53 questionnaires were distributed to all PHC physicians; of these, 41 completed the questionnaire. The overall response rate was $77.4 \%$.

\subsection{Sociodemographic Characteristics}

Table 1 shows that more than $46.3 \%$ of physicians were in the age range 30-39 years; males were overrepresented at $73.2 \%$. Seventy-eight percent of physicians working at extended health centres had postgraduate qualifications. $85.4 \%$ of the sample was of non-Omani background. In terms of clinical experiences, most of physicians (29.3\%) had between 5 and 9 years of experience and the less of them (17.1\%) has more than 20 years of experiences.

\subsection{Patient Factors}

Table 2 shows the common factors related to patients. Notably, $78 \%$ of physicians reported that the patient age group influenced their prescribing decisions; $75.6 \%$ of physicians reported that gender had an effect on their prescribing behaviour. Only $70.7 \%$ of physicians reported that untruthful patients or patient preferences for certain medications affected prescribing decisions. Frequent patient visits influenced $65.9 \%$ of physicians. Patients preferring advertised drugs affected the prescribing decisions of $63.4 \%$ of the physicians. Patient expectations and patient third part pressure had a considerable effect (48.8\%) on physicians.

\subsection{Physician Factors}

Table 3 shows that the most common factors related to the physician were the lack of treatment alternatives (70.7\%) followed by preserving the doctor-patient relationship (68.3\%). Other important physician factors included strict policies or guidelines and problems with drug availability, which were reported by the same percentage (65.9\%). Quality assurance manuals and adverse drug reactions influenced $63.4 \%$ and $61.0 \%$ of physicians, respectively. Only $41.5 \%$ of physicians reported that preferring familiar drugs and $41.5 \%$ of the needing to convey compassion had an influence on their prescribing decisions. 
Table 1. The socio-demographic Characteristics of the physicians participating in the study $(n=41)$

\begin{tabular}{lll}
\hline Characteristics & Frequency(n=41) & Percentage (\%) \\
\hline Sex & 30 & 73.2 \\
Male & 11 & 26.8 \\
Female & & \\
\hline Age group & 4 & 9.8 \\
$<\mathbf{3 0}$ & 19 & 46.3 \\
$\mathbf{3 0 - 3 9}$ & 16 & 39.0 \\
$\mathbf{4 0 - 4 9}$ & 2 & 4.9 \\
$>\mathbf{5 0}$ & & \\
\hline Working place & 32 & 78.0 \\
extended health centre & 9 & 22.0 \\
Health centre & & \\
\hline Nationality & 6 & 14.6 \\
Omani & 35 & 85.4 \\
Non-Omani & & \\
\hline Total clinical experience(years) & 12 & 29.3 \\
$\mathbf{5 - 9}$ & 11 & 26.8 \\
$\mathbf{1 0 - 1 4}$ & 11 & 26.8 \\
$\mathbf{1 5 - 1 9}$ & 7 & 17.1 \\
$>\mathbf{2 0}$ & & \\
\hline
\end{tabular}

Table 2. Patient factors influencing prescribing decisions $(n=41)$

\begin{tabular}{lll}
\hline \multirow{2}{*}{ Variables } & \multicolumn{2}{l}{ \% of participants responses } \\
\cline { 2 - 3 } & Dis-Agree & Agree \\
\hline Patient age group & $6(14.6 \%)$ & $32^{* *}(78 \%)$ \\
patient gender & $8(19.5 \%)$ & $31^{* * *}(75.6 \%)$ \\
Patient prefers certain medication & $7(17.1 \%)$ & $29^{* * *}(70.7 \%)$ \\
Patient expectation & $14(34.1 \%)$ & $20^{*}(48.8 \%)$ \\
language barriers & $18(43.9 \%)$ & $9(22 \%)$ \\
Higher education level & $17(41.5 \%)$ & $10(24.4 \%)$ \\
Social class & $23(56.1 \%)$ & $9(22 \%)$ \\
Patient medical knowledge & $24(58.5 \%)$ & $16^{*}(39 \%)$ \\
Untruthful patient & $7(17.1 \%)$ & $29^{* * *}(70.7 \%)$ \\
Patient gender hesitation & $24(58.5 \%)$ & $12(29.3 \%)$ \\
Patient third part pressure & $14(34.1 \%)$ & $20^{*}(48.8 \%)$ \\
Frequent visit & $7(17.1 \%)$ & $27^{* * *}(65.9 \%)$ \\
Patient prefer advertised drugs & $6(14.6 \%)$ & $26(63.4 \%)$ \\
Patient greatly influencing & $28^{* * *}(68.3 \%)$ & $8(19.5 \%)$ \\
\hline
\end{tabular}

*P $\leq 0.05, * * \mathrm{P} \leq 0.01, * * * \mathrm{P} \leq 0.001$. 
Table 3. Physicians Factors influencing prescribing decisions $(\mathrm{n}=41)$

\begin{tabular}{|c|c|c|}
\hline \multirow{2}{*}{ Variables } & \multicolumn{2}{|c|}{ \% of Participants responses } \\
\hline & Dis-Agree & Agree \\
\hline Need to give something & $16(39 \%)$ & $20 *(48.8 \%)$ \\
\hline Personal experience & $22(53.7 \%)$ & $16 *(39 \%)$ \\
\hline Preferring familiar drugs & $22(53.7 \%)$ & $17(41.5 \%)$ \\
\hline Need to convey compassion & $19(46.3 \%)$ & $17 *(41.5 \%)$ \\
\hline Uncertainty diagnosis & $23(56.1 \%)$ & $9(22 \%)$ \\
\hline Uncertainty treatment & $27(65.9 \%)$ & $8(19.5 \%)$ \\
\hline Quality Assurance Manual & $6(14.6 \%)$ & $26(63.4 \%)$ \\
\hline Supervisor visit & $26(63.4 \%)$ & $15(36.6 \%)$ \\
\hline To preserve doctor's patient relation & $8(19.5 \%)$ & $28 * * *(68.3 \%)$ \\
\hline To cut hospital cost & $29(70.7 \%)$ & $12(29.3 \%)$ \\
\hline Strict policies or guidelines & $8(19.5 \%)$ & $27 * * *(65.9 \%)$ \\
\hline Lack of time & $29(70.7 \%)$ & $7(19.4 \%)$ \\
\hline Lack of treatment alternative & $6(14.6 \%)$ & $29(70.7 \%)$ \\
\hline To avoid problem of drug unavailability & $10(24.4 \%)$ & $27(65.9 \%)$ \\
\hline ADRs effect 3 & $10(24.4 \%)$ & $25(61 \%)$ \\
\hline
\end{tabular}

$* \mathrm{P} \leq 0.05, * * \mathrm{P} \leq 0.01, * * * \mathrm{P} \leq 0.001$, ADRs: Adverse Drug Reactions.

\subsection{Pharmacist Factors}

Table 4 summarizes the pharmacist factors. The majority of physicians (87.8\%) reported that the pharmacist plays an important role in patient care. Seventy-eight percent of physicians stated that the pharmacist has an effective role in preventing medications errors. A total of $70.7 \%$ of physicians reported that the pharmacist should be contacted for advice in cases of uncertainty about therapy. Additionally, $65.9 \%$ of physicians agreed that pharmacists are the major medication expert in their health care institution. Furthermore, $63.4 \%$ of physicians agreed that the pharmacist frequently make an intervention in cases of medication errors. Surprisingly, only $36.6 \%$ of physicians agreed that the pharmacist greatly influences their prescribing decisions.

\subsection{Methods of Keeping Medical Knowledge Up to Date}

The methods used by clinicians to keep their medical knowledge up to date are summarized in Table 5 . The most influencing methods were private reading and the Internet, reported by $87.8 \%$ and $80.5 \%$ of physicians, respectively, followed by attending lectures or presentations $(78 \%)$ and reading medical journals $(70.7 \%)$.

Table 5. Methods of keeping Medical knowledge up to date influencing prescribing decisions $(\mathrm{n}=41)$

\begin{tabular}{lll}
\hline \multirow{2}{*}{ Variables } & \multicolumn{2}{l}{ Frequency (\%) of Participants responses } \\
\cline { 2 - 3 } & Dis-Agree & Agree \\
\hline Attending lectures/presentations & $6(14.6 \%)$ & $32^{* * *}(78 \%)$ \\
Private reading and study & $5(12.2 \%)$ & $36(87.8 \%)$ \\
Attending morning meeting & $28(68.3 \%)$ & $7(17.1 \%)$ \\
Working on a personal project & $15(36.6 \%)$ & $20(48.8 \%)$ \\
Study for post-graduate & $18(43.9 \%)$ & $18(43.9 \%)$ \\
Medical journals & $7(17.1 \%)$ & $29^{* * *}(70.7 \%)$ \\
Internet & $6(14.6 \%)$ & $33(80.5 \%)$ \\
\hline
\end{tabular}

$* \mathrm{P} \leq 0.05, * * \mathrm{P} \leq 0.01, * * * \mathrm{P} \leq 0.001$. 


\subsection{Sources of Prescribing Guidance}

Table 6 summarizes the sources of prescribing guidance utilized by clinicians. Consulting colleagues was the most frequently used source of prescribing guidance $(78 \%)$, followed by evidenced-based medical websites $(70.7 \%)$. Medication leaflets were also reported to have an effect on their prescribing decisions (65.9\%).

\section{Discussion}

The present study shows the statistically significant influence of patient age group and gender on physicians' prescribing decisions. Similar findings were reported (Lloyd, Harris, \& Roberts, 1995; Prescribing Support Unit. ASTRO-PUs, 2001; Roberts \& Harris, 1993; Roe, McNamara, \& Motheral, 2002; Schirm, Van Den Berg, Gebben, Sauer, \& De Jong-van den Berg, 2000; Sleator, 1993). Our results also revealed the statistically significant influence of patients' preferences for certain medications on physicians' prescribing decisions. Similar results were reported by Buusman, Andersen, Merrild, and Elverdam (2007). These authors showed that patient demands and requests were significant, and that some prescriptions were based on negotiations between general practitioners (GPs) and their patients. On the other hand, Toop et al. (2003) revealed that physicians were ambivalent about the selection of treatment in about $50 \%$ of cases in which patients demanded advertised drugs (odds ratio 7.1) compared with $12 \%$ for drugs not demanded by patients.

The results of the present study revealed that the lack of treatment alternatives (70.7\%) and strict policies or guidelines $(65.9 \%)$ had a significant influence on physicians' prescribing decisions. This is because the restricted PHC medications list plays a considerable role in influencing prescribing decisions. Our findings were compatible with a study conducted in Saudi Arabia showing that $70 \%$ of PHC physicians followed regulations or guidelines for the management of chronic/acute diseases at the health centre (Neyaz et al., 2011). The studies by Buusman et al. (2007); (Nutescu, Shapiro, Chevalier, \& Amin, 2005; Schumock et al., 2004) revealed that formulary statuses and policies restricting drug use are highly influential in the decision to use one analogue instead of another.

Our findings showed the influence of preserving the doctor-patient relationship, which is consistent with the study by Arroll et al. (2005). That study suggested that implementation of appropriate prescribing behaviour is influenced by the relationships that physicians have with individual patients, their hesitation to harm such relationships and their perceptions of patient characteristics.

Another significant influence was avoiding the problem of drug unavailability. This indicates the importance of social and logistic influences on prescribing decisions.

Regarding medication safety, physicians reported that adverse drug reactions had a significant effect on their prescribing decision. In agreement with our study, Bradley (1992) suggested that the most common source of concern was the potential side effects of a medication. Buusman et al. (2007); (Theodorou et al., 2009) showed that the adverse effects of a drug have a major impact on drug selection modification.

The majority of physicians in our study agreed that pharmacists play an important role in patient care. The same finding was found in a Dutch study, which showed that GPs have a positive impression regarding pharmacists' expertise and that there is sufficient support for the health care provided by pharmacists (Muijrers, Grol, Sijbrandij, Janknegt, \& Knottnerus, 2005). Furthermore, PHC physicians agreed that pharmacists frequently intervene in cases of medication errors. Our results were similar to a study by Carroll (2003), which suggested that in most cases of critical incidents, physicians received a phone call from a pharmacist or a long-term locum to change a medication. Carroll (2003) concluded that these interventions are likely to influence subsequent prescribing decisions.

Our results showed that pharmacists influence physicians' prescribing decisions. These results are supported by qualitative studies on prescribing in general practice, which have focused on clinical decision making or doctors' principles regarding choice of action prior to prescribing a drug. These studies concluded that clinical pharmacologists and community pharmacists probably have limited influence on GP prescribing (Bradley, 1991; Denig, Haaijer-Ruskamp, \& Zijsling, 1988; RK, SB, \& J, 1989; Skoglund, Segesten, \& Björkelund, 2007).

Methods to update medical knowledge appeared to be positively related to physicians' prescribing behaviour (Magzoub et al., 2011). In the present study, the most reported methods for keeping medical knowledge up to date were private reading and using the internet, which had an effect on physicians' prescribing decisions. This is because for most physicians, their available time and resources are critical factors; additionally, PHC physicians tend to be reactive recipients rather than active researchers of drug information (Arroll et al., 2005). A considerable number of physicians $(80.5 \%$ ) reported that the Internet was one of the common methods used to keep medical knowledge up to date. This result is in good agreement with a New Zealand study that found that nearly half of GPs searched the Internet for clinical information, and 37\% of them sought drug information on the Internet (Cullen, 2002). 
Colleagues were the most-utilized source of prescribing guidance reported. Our result is in consistent with the studies conducted in New Zealand and overseas, which showed that GPs are influenced by the hospital's prescription decision and that respected colleagues are influential prescribing leaders (Arroll et al., 2005). Smith (1996)stated that the validity of information from colleagues may be variable, but because GPs are most likely to ask colleagues whom they respect, they likely regard this information to be of high validity.

One of the limitations of the study is that all of the participants were from PHC institutions in one governorate of Oman. Therefore, the extent to which its findings can be generalized throughout Oman is uncertain. The second limitation is that the questionnaire reflects PHC physicians' self-reported views, which may have been biased. The need for a larger sample size, which may help in achieving further statistical power for the results obtained and improve the generalizability of the results. It is also recommended that the current study be undertaken in all PHC institutions in Oman, including both public and private sectors, and that it should be conducted across more than one region in Oman. This will increase sample size, allowing for better generalization of the findings and understanding of physicians' behaviours. Studies of clinical decision making are about people, behaviour and context. They require both quantitative and qualitative approaches to produce more comprehensive holistic views and more valid data.

\section{Conclusion}

Our study indicates that some prescribing decisions require a reasonable deal of thought. The prescriber struggles to balance several considerations to reach the best decision. Further, our findings disclose that rational prescribing is sometimes outweighed by other considerations that the physician fails to consider.

\section{Competing Interests Statement}

The authors declare that there are no competing or potential conflicts of interest.

\section{References}

Arroll, B., Goodyear-Smith, F., Patrick, D., Kerse, N., Harrison, J., Halliwell, J., . . Von Randow, M. (2005). Prescribing Information Resources: Use and preference by general practitioners An exploratory survey of general practitioners. Retrieved from https://researchspace.auckland.ac.nz/handle/2292/20847

Beijer, H., \& De Blaey, C. (2002). Hospitalisations caused by adverse drug reactions (ADR): a meta-analysis of observational studies. Pharmacy World and Science, 24(2), 46-54. https://doi.org/10.1023/A:1015570104121

Bradley, C. P. (1991). Decision making and prescribing patterns-a literature review. Family Practice, 8(3), 276-287. https://doi.org/10.1093/fampra/8.3.276

Bradley, C. P. (1992). Factors which influence the decision whether or not to prescribe: the dilemma facing general practitioners. Br J Gen Pract, 42(364), 454-458.

Buusman, A., Andersen, M., Merrild, C., \& Elverdam, B. (2007). Factors influencing GPs' choice between drugs in a therapeutic drug group. A qualitative study. Scandinavian Journal of primary health care, 25(4), 208-213. https://doi.org/10.1080/02813430701652036

Carroll, N. V. (2003). Do community pharmacists influence prescribing? Journal of the American Pharmacists Association, 43(5), 612-621. https://doi.org/10.1331/154434503322452256

Cullen, R. J. (2002). In search of evidence: family practitioners' use of the Internet for clinical information. Journal of the Medical Library Association, 90(4), 370.

Denig, P., Haaijer-Ruskamp, F., \& Zijsling, D. (1988). How physicians choose drugs. Social science \& medicine, 27(12), 1381-1386. https://doi.org/10.1016/0277-9536(88)90203-1

Khoja, T. A., Al-Shammari, S. A., Farag, M. K., \& Al-Mazrou, Y. (1996). Quality of prescribing at primary care centers in Saudi Arabia. Journal of Pharmacy Technology, 12(6), 284-288. https://doi.org/10.1177/875512259601200611

Lloyd, D., Harris, C., \& Roberts, D. (1995). Specific therapeutic group age-sex related prescribing units (STAR-PUs): weightings for analysing general practices' prescribing in England. BMJ, 311(7011), 991-994. https://doi.org/10.1136/bmj.311.7011.991

Magzoub, M., Neyaz, Y., Khoja, T., Qureshi, N., Haycox, A., \& Walley, T. (2011). Determinants of physicians' medication prescribing behaviour in primary care in Riyadh City, Saudi Arabia. Eastern Mediterranean Health Journal, 17(2). https://doi.org/10.26719/2011.17.2.160

Mossialos, E., Walley, T., \& Mrazek, M. (2004). Regulating pharmaceuticals in Europe: an overview. Regulating pharmaceuticals in Europe: striving for efficiency, equity and quality. Copenhagen, European observatory on 
health systems and policies, 1-37.

Muijrers, P. E., Grol, R. P., Sijbrandij, J., Janknegt, R., \& Knottnerus, J. A. (2005). Differences in prescribing between GPs. Impact of the cooperation with pharmacists and impact of visits from pharmaceutical industry representatives. Family Practice, 22(6), 624-630. https://doi.org/10.1093/fampra/cmi074

Neyaz, Y., Khoja, T., Qureshi, N., Magzoub, M., Hoycox, A., \& Walley, T. (2011). Medication prescribing pattern in primary care in Riyadh city, Saudi Arabia.

Nutescu, E. A., Shapiro, N. L., Chevalier, A., \& Amin, A. N. (2005). A pharmacologic overview of current and emerging anticoagulants. Cleveland Clinic journal of medicine, 72, S2-6. https://doi.org/10.3949/ccjm.72.Suppl_1.S2

O'Mahony, D., \& Gallagher, P. F. (2008). Inappropriate prescribing in the older population: need for new criteria. Age and ageing, 37(2), 138-141. https://doi.org/10.1093/ageing/afm189

Organisation for Economic Co-operation and Development. (2007). Health at aglance 2007: Focus on Quality of Care.

Prescribing Support Unit. ASTRO-PUs. (2001). Revision report. Retrieved from https://digital.nhs.uk/psu

RK, S., SB, S., \& J, A. (1989). Physician motivations for nonscientific drug prescribing. Retrieved from https://www.ncbi.nlm.nih.gov/pubmed/2648605

Roberts, S. J., \& Harris, C. M. (1993). Age, sex, and temporary resident originated prescribing units (ASTRO-PUs): New weightings for analysing prescribing of general practices in England. BMJ, 307(6902), 485-488. https://doi.org/10.1136/bmj.307.6902.485

Roe, C. M., McNamara, A. M., \& Motheral, B. R. (2002). Gender-and age-related prescription drug use patterns. Annals of Pharmacotherapy, 36(1), 30-39. https://doi.org/10.1345/aph.1A113

Schirm, E., Van Den Berg, P., Gebben, H., Sauer, P., \& De Jong-van den Berg, L. (2000). Drug use of children in the community assessed through pharmacy dispensing data. British journal of clinical pharmacology, 50(5), 473-478. https://doi.org/10.1046/j.1365-2125.2000.00275.x

Schumock, G. T., Walton, S. M., Park, H. Y., Nutescu, E. A., Blackburn, J. C., Finley, J. M., \& Lewis, R. K. (2004). Factors that influence prescribing decisions. Annals of Pharmacotherapy, 38(4), 557-562. https://doi.org/10.1345/aph.1D390

Skoglund, I., Segesten, K., \& Björkelund, C. (2007). GPs' thoughts on prescribing medication and evidence-based knowledge: the benefit aspect is a strong motivator: A descriptive focus group study. Scandinavian journal of primary health care, 25(2), 98-104. https://doi.org/10.1080/02813430701192371

Sleator, D. (1993). Towards accurate prescribing analysis in general practice: accounting for the effects of practice demography. Br J Gen Pract, 43(368), 102-106.

Smith, R. (1996). What clinical information do doctors need? Bmj, 313(7064), 1062-1068. https://doi.org/10.1136/bmj.313.7064.1062

Tamblyn, R. M., McLeod, P. J., Abrahamowicz, M., Monette, J., Gayton, D. C., Berkson, L., . . Isaac, L. M. (1994). Questionable prescribing for elderly patients in Quebec. CMAJ: Canadian Medical Association Journal, 150(11), 1801.

Theodorou, M., Tsiantou, V., Pavlakis, A., Maniadakis, N., Fragoulakis, V., Pavi, E., \& Kyriopoulos, J. (2009). Factors influencing prescribing behaviour of physicians in Greece and Cyprus: results from a questionnaire based survey. BMC health services research, 9(1), 150. https://doi.org/10.1186/1472-6963-9-150

Toop, L., Richards, D., Dowell, T., Tilyard, M., Fraser, T., \& Arroll, B. (2003). Direct to consumer advertising of prescription drugs in New Zealand: for health or for profit. Report to the Minister of Health supporting the case for a ban on DTCA. Dunedin: University of Otago, 2.

\section{Copyrights}

Copyright for this article is retained by the author(s), with first publication rights granted to the journal.

This is an open-access article distributed under the terms and conditions of the Creative Commons Attribution license (http://creativecommons.org/licenses/by/4.0/). 